\title{
Safety and Immunogenicity of High Molecular Weight Polysaccharide Vaccine from
}

\section{Immunotype 1 Pseudomonas aeruginosa}

\author{
Gerald B. Pier, Channing Laboratory and the Department of Medicine, \\ Brigham and Women's Hospital, Harvard Medical School, Boston, \\ Massachusetts 02115
}

A B S T R A C T The safety and immunogenicity of a high molecular weight polysaccharide from immunotype 1 Pseudomonas aeruginosa were tested in a dose response fashion in adult volunteers. The vaccine lacked toxicity and pyrogenicity for experimental animals. Doses of $50,75,150$, or $250 \mu \mathrm{g}$ were given to groups of individuals as a single dose subcutaneous injection. Doses of 150 and $250 \mu \mathrm{g}$ were associated with a significant rise in binding and opsonic antibody at 2 wk postimmunization. Titers remained unchanged for up to $6 \mathrm{mo}$. The vaccine was almost devoid of toxicity, eliciting no more than a slightly sore and tender arm at the site of injection. High molecular weight polysaccharide antigen appears to induce a good immune response following vaccination that is effective in mediating opsonophagocytic killing of live $P$. aeruginosa organisms.

\section{INTRODUCTION}

Infections caused by Pseudomonas aeruginosa have been particularly difficult to treat due to the organism's resistance to many antibiotics, the severity of the hosts' underlying condition that predisposes to P. aeruginosa infection, and the rapidity with which a septicemia can be fatal $(1,2)$. Immunotherapeutic modalities have been proposed as a potential means of increasing host resistance to this organism. Antibody directed towards cell surface lipopolysaccharide (LPS) ${ }^{1}$ determinants has been shown to be effective in mediating opsonophagocytic killing of $P$. aeruginosa (3, 4). This antibody has been detected in the serum of patients convalescing from $P$. aeruginosa sepsis $(5,6)$,

Received for publication 24 July 1981 and in revised form 28 September 1981.

${ }^{1}$ Abbreviations used in this paper: IT-1, immunotype 1; LPS, lipopolysaccharide. and survival of a P. aeruginosa sepsis episode has been associated with high levels of antibody to LPS in the acute phase serum (7). Attempts to induce antibody to LPS determinants in burn patients (8), cancer patients (9), and children with cystic fibrosis (10) have been hampered by the toxicity of LPS when used as a human vaccine. Nonetheless, these studies did suggest a drop in P. aeruginosa associated mortality following the use of an LPS vaccine. Recently, Jones et al. (11) documented the efficacy of a P. aeruginosa vaccine plus immunoglobulin in burn patients. Although the serologically active component of this vaccine has yet to be identified, the method of preparation (12) suggests it may be LPS.

A safe and immunogenic vaccine containing $P$. aeruginosa LPS serotype determinants would thus appear to be an ideal candidate for an immunotherapeutic agent to prevent $P$. aeruginosa sepsis. High molecular weight polysaccharide (PS) isolated from the supernate of $P$. aeruginosa cultures has been shown to be immunogenic in animals (13), to elicit protection to live organism challenge $(14,15)$ and to be nontoxic in mice and guinea pigs and nonpyrogenic in rabbits $(14,15)$. These PS antigens share serological specificity with the "O" specific side chain of LPS, yet differ from " $O$ " side chains by their immunogenicity, biochemical constituents, monosaccharide composition, and molecular size $(14,15)$. Intact LPS contains the toxic lipid A component that is lacking in PS. Rabbit antisera to PS antigens contains antibody primarily directed at the LPS " $O$ " side chain determinant, yet lacks anitbody to a second LPS-specific determinant present on the LPS molecule from all of the seven Fisher immunotypes of $P$. aeruginosa. ${ }^{2}$ Thus animal

\footnotetext{
${ }^{2}$ Pier, G. B., and D. M. Thomas. 1981. High molecular weight polysaccharide serotypes of Pseudomonas aeruginosa. Submitted for publication.
} 
studies have shown that PS is capable of inducing an antibody response directed at LPS serotype determinants, yet lacks the toxicity associated with LPS vaccines. The present study was designed to assess the immunogenicity and safety of a prototype PS vaccine isolated from the immunotype 1 (IT-1) strain of $P$. aeruginosa in adult human volunteers, including an assessment of the functional nature of the antibody induced.

\section{METHODS}

Vaccine. High molecular weight PS antigen was extracted from a 30 -liter culture of IT-1 P. aeruginosa grown in trypticase soy broth (Difco Laboratories, Detroit, Mich.) supplemented with $1 \%$ sodium acetate. After $48 \mathrm{~h}$ of growth, $300 \mathrm{~g}$ of hexadecyltrimethylammonium bromide was added and the precipitate and the organisms removed by centrifugation. The supernate was then concentrated to $800 \mathrm{ml}$ on an Amicon TCE 5 ultrafiltration apparatus using PM 30 membranes (Amicon Corp., Danvers, Mass.). The crude PScontaining material was precipitated from the concentrate by the addition of $4 \mathrm{vol}$ of $95 \%$ ethanol and recovered by centrifugation. This material was redissolved in phosphatebuffered saline $(0.1 \mathrm{M}$ phosphate, $0.15 \mathrm{M} \mathrm{NaCl}, \mathrm{pH} 7.2)$ heated at $60^{\circ} \mathrm{C}$ for $1 \mathrm{~h}$, and a one-tenth volume of $10 \%$ hexadecyltrimethylammonium bromide added to precipitate nucleic acids. After centrifugation, the supernate was recovered, crude PS precipitated by the addition of $4 \mathrm{vol}$ of $95 \%$ ethanol, and the above procedure for removing nucleic acids repeated twice. Following this, the crude PS was dissolved in $1 \%$ acetic acid, the $\mathrm{pH}$ adjusted to 5.0 with glacial acetic acid, and the solution heated at $90^{\circ} \mathrm{C}$ for $18 \mathrm{~h}$. This procedure cleaved the LPS into its lipid $A$ and "O" side chain components for subsequent removal. After cooling, the lipid A precipitate was removed by centrifugation, the supernate extracted 10 times with chloroform then twice with $90 \%$ phenol, precipitated with $4 \mathrm{vol}$ of $95 \%$ ethanol, redissolved in PBS, and applied to a Sephacyl S-300 column 2.6 $\times 100 \mathrm{~cm}$ in four separate runs. The serologically active material eluting between the void volume and the point where a 70,000-mol wt dextran marker begins to elute was collected, precipitated with alcohol, recovered, dialyzed, and lyophilized. This material was then weighed, dissolved to $1 \mathrm{mg} / \mathrm{ml}$ in pyrogen-free water with $1: 30,000$ merthiolate added and lyophilized as $1-\mathrm{mg}$ aliquots in individual vials. Sterility of the material was ascertained in bulk before packaging and in $10 \%$ of the final packaged material in accordance with the Food and Drug Administration regulations (Title 21, Sect. 610.12). Prior to injection the vaccines were reconstituted with an appropriate amount of sterile saline for injection to give the desired dosage in $0.5 \mathrm{ml}$.

Chemical analyses. Analyses for nucleic acids, proteins, LPS, lipids, phosphate, carbohydrate, monosaccharide components, and water were performed as described (13).

Animal toxicity studies. The general safety test using guinea pigs (Title 21, Section 610.11) was done in two Hartley strain animals weighing 325 and $345 \mathrm{~g}$. The animals were given $500 \mu \mathrm{g}$ of $P S$ in $5 \mathrm{ml}$ saline, observed and weighed daily. The growth rate of $21 \mathrm{~g}$ mice was observed following intraperitoneal injection of $500 \mu \mathrm{g} \mathrm{PS}$ in $0.5 \mathrm{ml}$ saline. Pyrogenicity was tested in three New Zealand White rabbits weighing between 2.04 and $2.50 \mathrm{~kg}$ following intravenous injection of $300 \mu \mathrm{g} / \mathrm{kg}$ body wt. Rectal temperatures were recorded prior to immunization and hourly for $3 \mathrm{~h}$ thereafter. Endotoxin contamination was tested for by the limulus lysate coagulation method (Sigma Chemical Co., St. Louis, Mo.). Two 12-kg rheuses monkeys were given four injections of $100 \mu \mathrm{g}$ of PS subcutaneously at 3-d intervals and observed for local and systemic reactions for $72 \mathrm{~h}$ after each injection. Sera were collected before injection and weekly for $4 \mathrm{wk}$ following the final injection.

Subjects. 42 normal healthy adult volunteers were asked to participate in this study. Signed informed consent was obtained, the volunteers randomly assigned to one of four groups receiving various doses of the vaccine, $20 \mathrm{ml}$ of blood obtained by venipuncture, then a $0.5-\mathrm{ml}$ subcutaneous injection of the vaccine given in the deltoid region of the arm. Subjects were interviewed at 24 and $48 \mathrm{~h}$ after the injection, symptoms noted, and temperatures recorded. Postimmunization sera were obtained at 14- and 28-d intervals following injection. For some subjects, serum was also obtained 6 mo postinjection.

Serologic methods. Serum antibody levels to the IT-1 PS were quantitated by means of a radioactive antigen binding assay using intrinsically labeled $\left[{ }^{14} \mathrm{C}\right] \mathrm{PS}$ prepared as previously described $(13,16)$. Sera were separated and stored at $-20^{\circ} \mathrm{C}$. Quantitation was performed as previously described for animal sera (16) except that five human sera were used to establish a standard curve. The correlation coefficient between percentage binding in the radioactive antigen binding assay vs. $\log _{10}$ microgram per milliliter of antibody was 0.901 .

Opsonophagocytosis assays were performed by an adaptation of the methods of Baltimore et al. (17) and Young (4). Human peripheral blood leukocytes were purified on a dextran gradient, freed of erythrocytes, and suspended to $10^{7}$ cells per milliliter. P. aeruginosa IT-1 was harvested in mid-log growth phase, washed once with minimal essential media (Microbiological Associates, Bethesda, Md.) and resuspended to $3 \times 10^{7}$ organisms $/ \mathrm{ml}$. The reaction mixture consisted of $100 \mu$ l of the serum or serum dilution to be tested, $100 \mu \mathrm{l}$ of cells, $100 \mu \mathrm{l}$ of organisms, and $100 \mu \mathrm{l}$ of a 1:5 dilution of guinea pig complement. A $25-\mu \mathrm{l}$ aliquot was removed from the tube at time 0 , diluted in distilled water to lyse the leukocytes, then further diluted in saline and plated out on trypticase soy agar plates for bacterial enumeration. A similar aliquot was removed following $60 \mathrm{~min}$ of incubation at $37^{\circ} \mathrm{C}$ where tubes were continuously mixed, and organisms counted. The opsonic titer of the serum was expressed as the reciprocal of the serum dilution killing $90 \%$ or more of the initial inoculum. Controls for each experiment included mixtures of two of three components (cells, serum, and complement) plus organisms and media.

Statistical methods. Differences in the concentration of antibody in preimmunization and postimmunization sera were compared by a $t$ test (18). Antibody titer rises of fourfold or greater in the opsonophagocytic assay were considered a positive response and analysis of responses between groups receiving different doses were compared by logistic regression (19).

\section{RESULTS}

Chemical analyses. The results of analyses for the various biochemical and monosaccharide constituents of the IT-1 high molecular weight PS are shown in 
TABLE I

Chemical Analyses of the P. aeruginosa IT-1 Vaccine

$\%$

$\begin{array}{lr}\text { Component } & \\ \text { Carbohydrate (Total) } & 72.5 \\ \text { Lipid } & <0.5 \\ \text { Phosphate } & <0.5 \\ \text { Nucleic acid } & 0.8 \\ \text { Protein } & 0.9 \\ \text { Water } & 22.2 \\ & \\ \text { Monosaccharide constituents } & \\ \text { Arabinose } & 6.1 \\ \text { Rhamnose } & 3.4 \\ \text { Mannose } & 62.2 \\ \text { Galactose } & 19.8 \\ \text { Glucose } & 8.5\end{array}$

Table I. Consistent with previously published results (13) the antigen was composed principally of carbohydrate, with low levels of contaminating nucleic acids, protein, and LPS. A high level of mannose was also found along with the previously reported monosaccharides of arabinose, rhamnose, galactose, and glucose (13).

Animal studies. The results of animal tests and in vitro coagulation of the limilus amebocyte lysate for toxicity indicated that the PS vaccine passed these tests with no indication of toxicity. These tests were performed on final packed material rehydrated with sterile saline for injection. No significant rises in temperature $\left(<0.5^{\circ} \mathrm{F}\right)$ were detected in rabbits given 300 $\mu \mathrm{g} / \mathrm{kg}$ body wt. Further lack of biologically active endotoxins was seen in the limulus lysate assay, where

TABLE II Analyses for Endotoxin Contamination by Gelation of the Limulus Amebocyte Lysate

\begin{tabular}{llll}
\hline & \multicolumn{3}{c}{ Component } \\
\cline { 2 - 4 } Amount & IT-1 PS & IT-1 & Escherichia coli \\
vaccine & LPS & LPS standard \\
\hline
\end{tabular}

ng

\begin{tabular}{rlll}
0.1 & - & - & - \\
0.5 & - & - & + \\
1.0 & - & + & + \\
10.0 & - & + & + \\
100.0 & - & + & + \\
$1,000.0$ & + & + & + \\
\hline
\end{tabular}

- Indicates gelation of lysate; - indicates no gelation after $24 \mathrm{~h}$. it took 1,000 times more vaccine than control LPS to gel the lysate (Table II). General toxicity tests in guinea pigs, mice, and monkeys revealed normal weight gains following injection of up to $500 \mu \mathrm{g}$ PS vaccine. The two monkeys given four $100-\mu$ g injections developed both binding antibody and titer rises of fourfold or greater by opsonophagocytosis.

Toxicity in human volunteers. Four different doses were given to volunteers: 7 persons received $50 \mu \mathrm{g}, 5$ persons received $75 \mu \mathrm{g}, 12$ persons received $150 \mu \mathrm{g}$, and 18 persons received $250 \mu \mathrm{g}$. Reactions to the PS vaccine were exceedingly mild, and no greater reaction than soreness and slight tenderness at the injection site were noted for any vaccinee at any dose, except for one person receiving $150 \mu \mathrm{g}$ who was scratched by the needle under the injection site and developed a slightly red and tender area lasting for $48 \mathrm{~h}$. No reaction lasted $>48 \mathrm{~h}$, and no erythema or induration was seen in any vaccinee other than as noted above. Slight soreness and tenderness at the injection site was seen in 1 of $7(14.3 \%)$ persons given $50 \mu \mathrm{g}, 1$ of $5(20 \%)$ persons given $75 \mu \mathrm{g}, 4$ of $12(33.3 \%)$ persons given 150 $\mu \mathrm{g}$, and 12 of $18(66.7 \%)$ persons given $250 \mu \mathrm{g}$.

Antibody response. The antibody responses of subjects in each of the four dosage groups 2 and 4 wk postimmunization, as quantitated in the radioactive antigen binding assay, are shown in Table III. There was no significant difference between preimmunization and postimmunization concentrations of antibody in the group given 50 of $75 \mu \mathrm{g}$ ( $t$ test). In the group given $150 \mu \mathrm{g}$ a significant $(P=0.004)$ difference in the mean pre- and postimmunization antibody concentrations were noted. Similarly, at $250 \mu \mathrm{g}$ a significant $(P$ $=0.002$ ) difference in antibody concentration was

TABLE III

Immunogenicity of PS Vaccine from IT-1 P. aeruginosa

\begin{tabular}{|c|c|c|c|}
\hline \multicolumn{4}{|c|}{ Antibody concentration geometric mean $\pm \mathrm{SD}$ (range), $\mu \mathrm{g} / \mathrm{ml}$} \\
\hline \multirow[b]{2}{*}{ Dose } & \multicolumn{3}{|c|}{ Weeks after immunization } \\
\hline & $\mathbf{0}$ & 2 & 4 \\
\hline$\mu g$ & & & \\
\hline 50 & $\begin{array}{l}13.2 \pm 12.8 \\
(3.9-40.0)\end{array}$ & $\begin{array}{c}30.5 \pm 29.2 \\
(4.0-88.4)\end{array}$ & $\begin{array}{c}31.2 \pm 30.3 \\
(4.0-86.8)\end{array}$ \\
\hline 75 & $\begin{array}{l}22.8 \pm 41.9 \\
(4.1-97.8)\end{array}$ & $\begin{array}{c}42.8 \pm 73.9 \\
(3.8-174.3)\end{array}$ & $\begin{array}{c}44.5 \pm 76.8 \\
(3.8-175.2)\end{array}$ \\
\hline 150 & $\begin{array}{c}5.9 \pm 3.6 \\
(1.7-14.9)\end{array}$ & $\begin{array}{c}63.8 \pm 55.8 \\
(6.1-147.4)\end{array}$ & $\begin{array}{c}66.7 \pm 54.3 \\
(6.1-155.8)\end{array}$ \\
\hline 250 & $\begin{array}{c}4.9 \pm 1.9 \\
(3.6-10.2)\end{array}$ & $\begin{array}{l}55.9 \pm 61.8 \\
(3.7-250)\end{array}$ & $\begin{array}{l}56.3 \pm 59.3 \\
(3.7-232)\end{array}$ \\
\hline
\end{tabular}


TABLE IV

Duration of Antibody Levels in Persons Receiving 150 $\mu \mathrm{g}$ of IT-1 P. aeruginosa PS Vaccine

\begin{tabular}{ccc}
\hline \multicolumn{3}{c}{ Antibody concentration in $\mu \mathrm{g} / \mathrm{ml}$-geometric mean \pm SD (range) } \\
\hline \multicolumn{3}{c}{ Time after immunization } \\
\hline $5.9 \pm 3.6$ & $32.7 \pm 29.3$ & $\begin{array}{c}\text { Difference } \\
\text { (post-pre) }\end{array}$ \\
$(1.7-14.9)$ & $(4.2-94.2)$ & $27.3 \pm 28.8$ \\
& & $(1.1-87.4)$ \\
\hline
\end{tabular}

noted. No significant difference was noted in the geometric mean antibody titer achieved at 2 wk when compared to $4 \mathrm{wk}$ by a pooled $t$ test, and no significant difference was noted between the geometric mean antibody concentration achieved in the sera of vaccinees receiving $150 \mu \mathrm{g}(63.8 \mu \mathrm{g} / \mathrm{ml})$ vs. that achieved at the $250-\mu \mathrm{g}$ dosage $(55.9 \mu \mathrm{g} / \mathrm{ml})$. Serum antibody levels present at 6 mo following immunization with $150 \mu \mathrm{g}$ are shown in Table IV. The decrease in individual antibody levels was not significant, indicating maintenance of antibody titers during this interval.

Functional properties of the induced antibodies were measured in an opsonophagocytosis test, and the titers determined for pre- and day 14 postimmunization sera are shown in Table V. 3 of 7 persons receiving $50 \mu \mathrm{g}$ had a fourfold or greater increase in titer in this assay, while 2 of 5 persons receiving 75 $\mu \mathrm{g}, 9$ of 12 persons receiving $150 \mu \mathrm{g}$, and 16 of 18 persons receiving $250 \mu \mathrm{g}$ had these responses. In the total population, 32 persons had preimmunization titers of two or less, 8 had preimmunization titers of four through eight and 2 had preimmunization titers of more than eight. After immunization, 7 persons had titers of 2 or less, 13 had titers of $4-8$ and 23 had titers of $1: 16$ or greater, up to $1: 128$. Logistic regression analyses of the dose response effect was performed on these data. Responses were designated 1 or 0 to indicate whether or not a fourfold or greater titer rise had occurred. The responses at 50 and $75 \mu \mathrm{g}$ were treated as one category (low dose) for these statistical purposes. A highly significant difference $(P<0.001)$ was observed between the response seen in the group immunized with 150 and $250 \mu \mathrm{g}$, when compared to the response of the 50- and 75- $\mu$ g group. The difference in response between 150- and 250- $\mu \mathrm{g}$ doses was marginally significant, $(P=0.079)$. This suggested a trend for the higher dose being slightly more efficacious in inducing a functional antibody response.

\section{DISCUSSION}

Disease due to $P$. aeruginosa infections is most often seen in immunocompromised or traumatized hosts. Susceptibility to infection has been thought to be correlated with granulocytopenia (2), though the underlying host condition was found to be a better indicator of the severity and outcome of $P$. aeruginosa sepsis (20). These immunocompromised patients, who are at risk for developing $P$. aeruginosa infections, are altered in their responses to immunological stimuli, and therefore may not respond to the PS antigen with humoral antibody, as was shown here for normal volunteers. Vaccination of granulocytopenic populations generally results in poor immune responses, but there are certain populations who are at high risk for $P$. aeruginosa infections that can be immunized prophylactically. Other populations, such as burn and trauma victims, may respond adequately to vaccination if given soon enough after injury. Immunosuppressed populations can potentially be immunized before or in between courses of therapy. Since the PS vaccine used here induced both binding and opsonic antibody, and has minimal toxicity in vaccinees, it offers the possibility to function as an effective immunotherapeutic agent for preventing P. aeruginosa sepsis.

TABLE V

Serum Titers in the Opsonophagocytosis Assay following Immunization with P. aeruginosa IT-1 PS Vaccine

\begin{tabular}{|c|c|c|c|c|c|c|c|c|}
\hline \multirow[b]{2}{*}{ Dose } & \multirow{2}{*}{$\begin{array}{l}\text { Number } \\
\text { immunized }\end{array}$} & \multicolumn{3}{|c|}{ Preimmunization titer } & \multicolumn{3}{|c|}{ Postimmunization titer } & \multirow{2}{*}{$\begin{array}{l}\text { No. persons with } \\
\text { fourfold or } \\
\text { greater rise }\end{array}$} \\
\hline & & $\leq 2$ & $4-8$ & $>8$ & $\leq 2$ & $4-8$ & $>8$ & \\
\hline \multicolumn{9}{|l|}{$\mu g$} \\
\hline 50 & 7 & $5^{\circ}$ & 2 & 0 & 3 & 2 & 2 & 3 \\
\hline 75 & 5 & 4 & 1 & 0 & 3 & 1 & 1 & 2 \\
\hline 150 & 12 & 9 & 1 & 2 & 1 & 5 & 6 & 9 \\
\hline 250 & 18 & 14 & 4 & 0 & $\mathbf{0}$ & 5 & 13 & 16 \\
\hline
\end{tabular}

- Represents number of vaccinees with this titer. 
PS antigens are prepared by a method utilizing heat and acid to cleave the contaminating LPS into its lipid $A$, " $O$ " side chain and core components for subsequent elimination. This somewhat harsh method was chosen because it was found to be the only method that removed all detectable intact LPS. Although low levels of LPS contamination in a vaccine may not be of any concern if the toxicity is within acceptable limits, animal studies of numerous $P$. aeruginosa vaccines have often indicated that contaminating LPS is the responsible agent for the immunogenicity and protective efficacy seen (14). The immunogenicity of this PS vaccine in humans, coupled with its almost total lack of toxicity, indicates that the acetic acid method for elimination of LPS is not only an effective procedure for reducing toxicity, but does not interfere with immunogenicity.

The magnitude of the human immune response to PS is particularly good when compared to the amount of antibody inducible in experimental animals (16). Humans by far had a greater degree of response than we have found for the most responsive laboratory animal, the $\mathrm{C}_{3} \mathrm{H}$ mouse strain. The opsonic titers we obtained in our vaccinees was also close to that reported by Young and Armstrong (3) and Young (4) for patients recovering from $P$. aeruginosa sepsis or immunized with an LPS vaccine. The opsonophagocytosis test they used was very similar to the one used here, except that they multiplied their titers by a factor of 10 to translate the $0.1-\mathrm{ml}$ amount of serum used in the reaction mixture to $1.0 \mathrm{ml}$. The data here report the dilution of a 0.1-ml amount of serum that elicited killing. Another slight difference was their use of $\geq 70 \%$ reduction in viable organisms as representing killing, while we used $\geq 90 \%$ levels. Taking this into account, the phagocytic titers of 12 persons recuperating from $P$. aeruginosa bacteremia ranged from 32 to 2,048 (our method), with 8 of these patients $(66.7 \%)$ having titers of $32-$ 128. 12 of $18(66.7 \%)$ of the PS vaccinees receiving $250 \mu \mathrm{g}$ had titers of 16-128. None of the immunized individuals had a titer of $>128$, whereas 4 of 12 of the infected patients did. Similarly in Young's (4) study of the opsonic titers of humans given monovalent preparations of $P$. aeruginosa LPS, opsonic titers of 2562,048 were obtained. Although these titers are slightly higher than those obtained by PS vaccination, the dose of LPS used was quite high when compared to PS (25 $\mu \mathrm{g} / \mathrm{kg}$ LPS vs. an average of $3.5 \mu \mathrm{g} / \mathrm{kg}$ PS) was given in five doses when compared with the single dose of PS, and was associated with local reactions not seen with PS immunization.

The influence of antibody levels of $P$. aeruginosa LPS serotype determinants in affecting the outcome of $P$. aeruginosa infection has been suggested by both vaccine studies $(8,9,11)$ and also by a study of the influence on survival of acute phase antibody levels to LPS (7). Our studies in animals, $(14,15)$ indicate that PS induces a serotype specific immune response against the LPS " $O$ " side chain determinant. Further study is required to assess whether the human immune response to $P S$ vaccination also induces a response to LPS specific determinants. The data here do indicate that immunization with PS leads to an immune response in humans, that the antibody elicited can function in opsonizing live organisms, and that PS vaccination is associated with a minimal level of toxicity in vaccinees.

\section{ACKNOWLEDGMENTS}

I am indebted to Dr. J. M. Griffiss and Dr. D. L. Kasper for their assistance in the clinical aspects of this work; to the members of the Channing Laboratory Staff, Childrens Hospital Medical Center Bacteriology Laboratory, the Laboratory of Dr. D. D. Eardley, Harvard School of Public Health, and others for their willingness to volunteer for this study. I am also indebted to Dr. George Grady, Dr. George Wright, and Ms. Leslie Wetterlow of the Massachusetts State Laboratory Institute for their assistance in packaging, sterility and animal toxicity testing of the vaccine. I gratefully acknowledge the skilled technical assistance of Ms. Diane M. Thomas and the secretarial assistance of Ms. Barbara Chamberlain.

This work was supported by contract DAMD 17-79C-9050 from the United States Army Medical Research and Development Command. The views presented in this manuscript are those of the author and should not be construed as an official Department of the Army position unless so designated by other documents.

\section{REFERENCES}

1. Bodey, C. P., and V. Rodriquez. 1973. Advances in the management of Pseudomonas aeruginosa in cancer patients. Eur. J. Cancer. 9: 435-441.

2. Flick, M. R., and L. C. Cluff. 1976. Pseudomonas in bacteremia. Review of 108 cases. Am. J. Med. 60: 501508.

3. Young, L. S., and D. Armstrong. 1972. Human immunity to Pseudomonas aeruginosa. I. In vitro interaction of bacteria, polymorphonuclear leukocytes, and serum factors. J. Infect. Dis. 126: 257-276.

4. Young, L. S. 1972. Human immunity to Pseudomonas aeruginosa. II. Relationship between heat stable opsonins and type-specific lipopolysaccharides. J. Infect. Dis. 126: 277-287.

5. Young, L. S., B. H. Yu, and D. Armstrong. 1970. Agargel precipitating antibody in Pseudomonas aeruginosa infections. Infect. Immun. 2: 495-503.

6. Crowder, J. G., M. W. Fisher, and A. White. 1972. Type specific immunity in Pseudomonas diseases. J. Lab. Clin. Med. 79: 47-54.

7. Pollack, M., and L. S. Young. 1979. Protective activity of antibodies to exotoxin $\mathrm{A}$ and lipopolysaccharide at the onset of Pseudomonas aeruginosa septicemia in man. J. Clin. Invest. 63: 276-286. 
8. Alexander, J. W., and M. W. Fisher. 1974. Immunization against Pseudomonas in infection after thermal injury. J. Infect. Dis. 130(Suppl.): S152-S158.

9. Young, L. S., R. D. Meyer, and D. Armstrong. 1973. Pseudomonas aeruginosa vaccine in cancer patients. Ann. Intern. Med. 79: 518-527.

10. Pennington, J. E., H. Y. Reynolds, R. E. Wood, R. A. Robinson, and A. S. Levine. 1975. Use of Pseudomonas aeruginosa vaccine in patients with cystic fibrosis. Am. J. Med. 58: 629-636.

11. Jones, R. J., E. A. Roe, and J. L. Gupta. 1980. Controlled trial of Pseudomonas immunoglobulin and vaccine in burn patients. Lancet. II: 1263-1265.

12. Miller, J. M., J. F. Spilsbury, R. J. Jones, E. A. Roe, and E. J. L. Lowbury. 1977. A new polyvalent Pseudomonas vaccine. J. Med. Microbiol. 10: 19-27.

13. Pier, G. B., H. F. Sidberry, S. F. Zolyomi, and J. C. Sadoff. 1978. Isolation and characterization of high molecular weight polysaccharide from the slime of Pseudomonas aeruginosa. Infect. Immun. 22: 908-918.

14. Pier, G. B., H. F., Sidberry, and J. C. Sadoff. 1978. Protective immunity induced in mice by immunization with high molecular weight polysaccharide from Pseudomonas aeruginosa. Infect. Immun. 22: 919-925.
15. Pier, G. B., H. F. Sidberry, and J. C. Sadoff. 1981. High molecular weight polysaccharide antigen from immunotype 2 Pseudomonas aeruginosa. Infect. Immun. 34: 461-468.

16. Pier, G. B., R. B. Markham, and D. D. Eardley. 1981. Correlation of the biological responses of $\mathrm{C} 3 \mathrm{H} / \mathrm{HeJ}$ mice to endotoxin with the chemical and structural properties of the lipopolysaccharides from Pseudomonas aeruginosa and Escherichia coli. J. Immunol. 127: 184-197.

17. Baltimore, R. S., D. L. Kasper, C. J. Baker and D. K. Goroff. 1976. Opsonophagocytic antibody and immunity to type III Group B streptococci. Pediatr. Res. 10: 395402.

18. Snedecor, G. W., and W. C. Cochran. 1967. Statistical Methods. Iowa State University Press, Ames, Iowa. pp. 3-593.

19. Cox, D. R. 1970. Analyses of Binary Data. Chapman and Hall. New York, N. Y.

20. Reynolds, H. V., A. S. Levine, R. E. Wood, C. H. Wierdt, D. C. Dale, and J. E. Pennington. 1975. Pseudomonas aeruginosa infections. Persisting problems and current research to find new therapies. Ann. Intern. Med. 82: 819-831. 